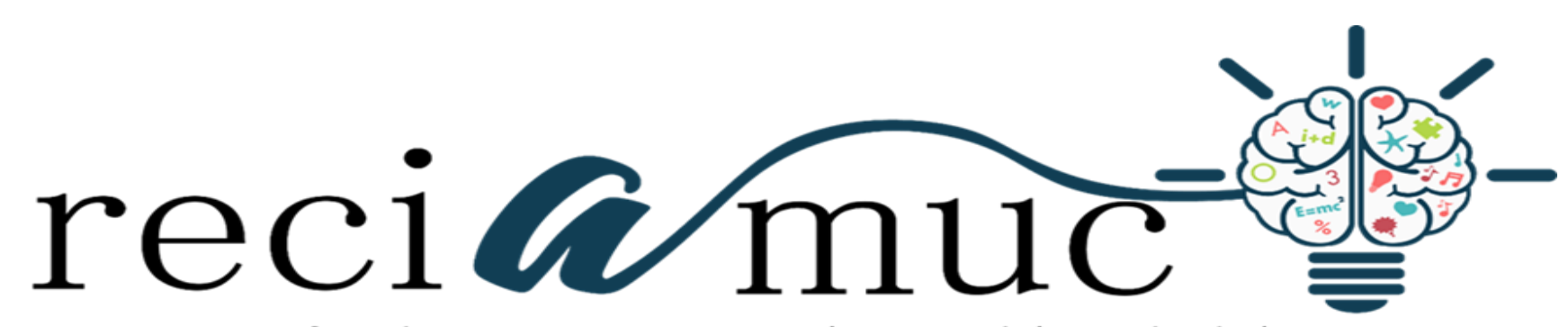

Revista científica de investigación actualización del mundo de las ciencias

Héctor Gonzalo Macías Lozano a; Rosendo Eduardo Loza Menendez ${ }^{\text {b; }}$ Davina Guerrero Vardelly ${ }^{\mathrm{c}}$

Aplicación de la medicina natural y tradicional en odontología

Application of natural and traditional medicine in dentistry

Revista Científica de Investigación actualización del mundo de las Ciencias. Vol. 3 núm., 2, abril, ISSN: 2588-0748, 2018, pp. 756-780

DOI: $10.26820 /$ reciamuc/3.(2).abril.2019.756-780

URL: http://reciamuc.com/index.php/RECIAMUC/article/view/365

Código UNESCO: 3213.13 Estomatología

Tipo de Investigación: Artículo de Revisión

(C) RECIAMUC; Editorial Saberes del Conocimiento, 2019

Recibido: $15 / 01 / 2019$

Aceptado: 07/02/2019

Publicado: 01/04/2019

Correspondencia: hector.maciasl@ug.edu.ec

a. Magister en Docencia y Gerencia en Educación Superior; Diplomado en Docencia Superior; Doctor en Odontología; Universidad de Guayaquil; Guayaquil, Ecuador; hector.maciasl@ug.edu.ec

b. Magister en Docencia y Gerencia en Educación Superior; Diplomado en Docencia Superior; Doctor en Odontología; Universidad de Guayaquil; Guayaquil, Ecuador; eduardo.lozam@ug.edu.ec

c. Odontóloga; Universidad de Guayaquil; Guayaquil, Ecuador; davina.guerrerov@ug.edu.ec 


\section{Aplicación de la medicina natural y tradicional en odontología}

Vol. 3, núm. 2., (2019)

Héctor Gonzalo Macías Lozano; Rosendo Eduardo Loza Menendez; Davina Guerrero Vardelly

\section{RESUMEN}

La medicina natural, o naturismo, es un método curativo que pone en múltiples usos elementos naturales que permiten que el individuo haga adquisición de un nivel máximo de salud en su estilo de vida. Con el propósito de ofrecer una actualización de los conocimientos sobre la aplicación de la Medicina Natural y Tradicional en Odontología, se efectuó una revisión bibliográfica exhaustiva al respecto basado en la información obtenida de textos y revistas consultadas en centros de referencias y a través de localizadores electrónicos como Pubmed, Medline y Google de los últimos años. Según pudimos constatar esta temática tiene vigencia y su aplicación resulta de gran utilidad en el tratamiento de las afecciones odontológicas.

Palabras clave: Medicina natural; Medicina tradicional; Medicina bioenergética. 


\title{
Aplicación de la medicina natural y tradicional en odontología
}

Vol. 3, núm. 2., (2019)

Héctor Gonzalo Macías Lozano; Rosendo Eduardo Loza Menendez; Davina Guerrero Vardelly

\begin{abstract}
Natural medicine, or naturism, is a healing method that puts multiple elements in natural uses that allow the individual to acquire a maximum level of health in their lifestyle. With the purpose of offering an update of the knowledge about the application of Natural and Traditional Medicine in Dentistry, an exhaustive bibliographic review was made based on the information obtained from texts and journals consulted in reference centers and through electronic locators such as Pubmed, Medline and Google in recent years. As we could see, this theme is valid and its application is very useful in the treatment of dental conditions.
\end{abstract}

Key words: Natural medicine; Traditional medicine; Bioenergetic Medicine. 


\section{Aplicación de la medicina natural y tradicional en odontología}

Vol. 3, núm. 2., (2019)

Héctor Gonzalo Macías Lozano; Rosendo Eduardo Loza Menendez; Davina Guerrero Vardelly

\section{Introducción.}

El origen de las ciencias médicas data de tiempos remotos; esta generalmente confundida por un grupo, con el empirismo, y por otro, con la superstición. El primer inicio del nacimiento de la medicina popular, fundamentos en la observación rudimentaria de los fenómenos de orden médico que es perdurable entre los pueblos salvajes; en tanto la superstición provoco el origen de la medicina sacerdotal apareciendo en las primeras edades de la gran mayoría de los pueblos y explicada también por la mayor ilustración de los ministros del culto respecto a una masa popular sumergida en la ignorancia.

La visión de Hipócrates reveló a un poderoso genio que iluminó toda una época, nombrado por criterios racionales y natural del llamado Padre de la medicina, puso de manifestó la observación clínica de la evolución de la enfermedad, con facultades objetivas y muy completas; se ha añadido poco a estos por la ciencia moderna: Aporto que entre las causas de las enfermedades se incluyen: la herencia, el clima, el suelo, las aguas, los vientos y también la temperatura, además se le concede destacada importancia a la balneación, los ejercicios físicos y la dieta; son descritas la sangrías, escarificaciones y las ventosas, atribuyéndosele gran importancia al pronóstico para el cual fueron establecidas reglas generales.

Sucesores, del padre de la medicina como Diocles, Praxágoras, Dexipo y Filistion, se comprometieron mucho más que su maestro a las ideas sistemática y ante todo al naturismo. Es de continuada tradición helénica en Alejandría donde sobresalen talentosamente los nombres de Herófilo y Erasístrato, referidos en el empirismo y el dogmatismo mecánico: No fue tardía 


\section{Aplicación de la medicina natural y tradicional en odontología}

Vol. 3, núm. 2., (2019)

Héctor Gonzalo Macías Lozano; Rosendo Eduardo Loza Menendez; Davina Guerrero Vardelly

fundarse con el nombre de Dogmática, una escuela que, tuvo la pretensión de seguir las tradiciones hipocráticas; pero desvirtuó estas con una serie de fantasías y especulaciones.

La medicina romana comenzó siendo en parte teúrgica y empírica, aunque no tardó, con los progresos de la civilización, en sentirse la influencia helénica. Partiendo ya de la época de las guerras púnicas fueron surgiendo numerosos médicos griegos, siendo el célebre fue Asclepíades, pero no adquirió su verdadero auge hasta el encuentro de Galeno, el cual desarrollo extensos estudios en anatomía, así como resumió los conocimientos terapéuticos de la época, sintetizando cautelosamente elementos de conocimientos plasmado en las obras de Dioscórides, Filón de Alejandría, Pablo de Tarso, Escribonio Largo, Sestionigele y Andrómaco; referidos a la patologías, se mantuvo partidario de la escuela hipocrática.

Evidentemente en todas las épocas la medicina se ha centrado naturista, casi impuesta por los fundadores de cada escuela, como figura primada en el desarrollo de esta ciencia a lo largo de los años. (Pascual Casamayor, Pérez Campos, Morales Guerrero, Castellanos Coloma, \& Gónzalez Heredia, 2014).

La Medicina Natural y Tradicional (MNT), atendiendo a su denominación, es considerada una corriente que conjuga al pensamiento y la actuación terapéutica albergando una diversidad de expresiones concretas, muchas de ellas provienen de culturas ancestrales o relativamente antiguas, las otras mucho más recientes o no correspondida a alguna tradición. Algunas recurren a recursos íntegramente naturales, otras a medios de alto nivel tecnológico. En principio, tienen en comúnmente el de responder a los cánones de la práctica médica convencional. La Medicina Natural y Tradicional forma parte del cumulo cultural de la humanidad, la cual se viene 


\section{Aplicación de la medicina natural y tradicional en odontología}

Vol. 3, núm. 2., (2019)

Héctor Gonzalo Macías Lozano; Rosendo Eduardo Loza Menendez; Davina Guerrero Vardelly

desarrollando en múltiples países con características muy propias, con tendencias a los recursos disponibles en ellos y sobre la base de la idiosincrasia de los habitantes de cada región, por lo que es el resultado de una evolución manifiesta con lentitud, pero avalada por la experiencia práctica. (Nicot Cos, Nicot Mesa, Masó Baro, \& Balbuena Daudinot, 2014)

Remontándonos a la creación del universo, cabe aludir que la existencia del empleo de las plantas para la alimentación del hombre y la curación de diversas enfermedades: Siempre han sido de importante utilización; experiencia transmitida de generación en generación, a tal punto, que en la actualidad en el de cursar del siglo XXI, son plateadas como plantas de uso tradicional, lo que por su relevante significación es pensable que tendrá duración hasta el fin de los tiempos.

Aunque escritos revisados han dejados constancia al respecto, que la medicina herbaria, también conocida como medicina botánica, fitoterapia o fitomedicina, ha sido la forma más antigua de atención médica que se ha conocido en la humanidad. Actualmente permanecen extensas documentaciones y estudios de investigaciones científicas relacionadas con el uso de las plantas para la cura diversas de enfermedades.

La Medicina tradicional y Natural está contemplada como una disciplina medica grandemente reconocida; manifestada y enfocada en función de las necesidades significadas por los servicios de salud; por lo que resulta de relevante importancia el conocimiento y aplicación de los procederes y técnicas de promoción de salud ; prevención de enfermedades ; diagnostico ; curación ; habilitación y rehabilitación, comprendido la MTN en busca de más vida y sobre todo de mayor calidad de vida; es generalizada la utilización de medicamentos naturales y otros recursos terapéuticos de fácil adquisición, poco costo y al alcance de todos; por ello se considera 


\section{Aplicación de la medicina natural y tradicional en odontología}

Vol. 3, núm. 2., (2019)

Héctor Gonzalo Macías Lozano; Rosendo Eduardo Loza Menendez; Davina Guerrero Vardelly

como apta para transformación de la manera de ver la medicina, la vida y hasta el mismo universo. En este orden es una ciencia transdisciplinaria cuya intención y finalidad es la apropiación de conocimientos y el manejo de las actividades que permitan la restitución, fomento y promoción de la salud, teniendo en consideración los elementos ecológicos, sociales, mentales, físicos y espirituales.

Entrando en especificas consideraciones, la Medicina Natural y Tradicional contempla y enaltece al hombre como un todo integro, correspondido en su totalidad y dentro de un aspecto ecológico, partiendo de que la falta de salud o la enfermedad están precedidos de un desequilibrio de él en su sistema ecológico en su totalidad y no sólo del agente causal y la evolución patógena.

La mejor y mayor asistencia sanitaria no es basada en las prácticas de costosos tratamientos y sofisticados equipos desde el punto de vista tecnológico, sino, en educar sanitariamente a la población en la utilización de los sustentos químicos fiscos y biológicos de la naturaleza; el conocimiento bioenergético, el uso de las plantas, agua, luz, aire, sol, arcilla y alimentos; así como el empleo de técnicas fisioterapéuticas y la búsqueda de terapias me- nos agresivas y sin efectos secundarios. (Bellon Leyva, Echarry Cano, \& Aldana Bello, 2013), (Pargas Torres, 2005)

En los momentos actuales, así como en contraposición de los novedosos avances alcanzados en la creación y promoción de nuevos medicamentos en el mundo; continúa de manera acertada la utilización de la MNT, cobrando cada día más defensores y ejecutores, fundamentalmente por las formas naturales de curación y a las carencias de efectos secundarios de estas terapias. (Bellon Leyva, Echarry Cano, \& Aldana Bello, 2013) 


\section{Aplicación de la medicina natural y tradicional en odontología}

Vol. 3, núm. 2., (2019)

Héctor Gonzalo Macías Lozano; Rosendo Eduardo Loza Menendez; Davina Guerrero Vardelly

Desde la década de los años 70 La Organización Mundial de la Salud ha promovido el uso de modalidades de la MNT que resulten eficaces y seguras para el cuidado de la salud, con el verdadero criterio de su integración a los diferentes sistemas médicos nacionales; esto ilumina y revela la misión de la OMS consistente en mejorar la salud y ayudar a salvar vidas; en referido a la MNT con énfasis a promover esas funciones, la OMS: (Guillaume Ramírez, Ortiz Gómez, Álvarez Artímez, \& Marín Quintero, 2017)

- Facilita la integración de la MNT en los sistemas de salud mediante su apoyo a los Estados Miembros en el desarrollo de sus propias políticas nacionales para ese sector.

- Elabora directrices sobre MNT por medio de la confección y el establecimiento de normas, directrices técnicas y metodologías dirigidas a la investigación de productos, prácticas y profesionales.

- Alienta la investigación estratégica en materia de MNT, respaldando proyectos de investigación clínica sobre su seguridad y eficacia.

- Aboga por el uso racional de la MNT mediante el fomento de su utilización basada en pruebas científicas.

- Difunde información sobre MNT, actuando como centro coordinador para facilitar el intercambio de información. (OMS, 2013)

\section{Metodología}

Se realizó una revisión con respecto al tema consultándose 11 referencias bibliográficas de prestigiosas revistas científicas con un alto grado de actualidad que nos permitió desarrollar la historia, sus ramas y su aplicación en la Odontología. 


\section{Aplicación de la medicina natural y tradicional en odontología}

Vol. 3, núm. 2., (2019)

Héctor Gonzalo Macías Lozano; Rosendo Eduardo Loza Menendez; Davina Guerrero Vardelly

Ramas de la medicina natural y tradicional. (Este es un aspecto de gran importancia para el hombre, dentro de sus sociedades, para que sepa discernir el contexto de cada uno de ellos).

\section{Homeopatía:}

Su significado proviene de la palabra homeopatía proviene de (2 palabras griegas homeos, que significa similar, y pathos, enfermedad): La homeopatía es un sistema de medicina dedicados a las enfermedades con cantidades muy diminutas de un agente o de un fármaco que provoca síntomas de la enfermedad dada, cuando se administra a una persona sana; lo que fundamenta esta práctica es "lo igual se cura con lo igual". Los remedios homeopáticos son provenientes de una gama de plantas, minerales y también de substancias químicas.

\section{Medicina física:}

Es caracterizada por las medidas físicas a tomar; con tal finalidad de tratar la situación patológica determinada de un individuo; tendremos algunas de las prácticas incluidas en este grupo:

- La fisioterapia: que comprende los ultrasonidos, la diatermia y otros agentes de energía electromagnética; la hidroterapia definida como el uso del agua de diversas maneras; caliente, fría, vapor y hielo y sus aplicaciones; baños de espuma o de burbujas, duchas, surtidores, bañeras calientes, cataplasmas, vendas, fomentos, baños de pies, entre otras, para el mantenimiento y fomentar la salud. Es uno de los tratamientos más antiguos que se conoce, y en muchas culturas, ya utilizaban este método para curar las enfermedades y heridas, el masaje, la movilización de articulaciones (manipulación) y las técnicas de inmovilización. 


\section{Aplicación de la medicina natural y tradicional en odontología}

Vol. 3, núm. 2., (2019)

Héctor Gonzalo Macías Lozano; Rosendo Eduardo Loza Menendez; Davina Guerrero Vardelly

\section{Dietoterapia o tratamiento dietético:}

Indistintamente es la base de la medicina natural, día a día son más las personas que conocen sus propiedades y consumen alimentos integrales y suplementos dietéticos, para la conservación y mantenimiento de salud, y como tratamiento contribuyente de enfermedades.

\section{Acupuntura Digitopuntura:}

Expresa como una rama de la Medicina Natural y Tradicional, nombre que se le ha otorgado al procedimiento terapéutico chino Tshen Zin que consiste en la aplicación de agujas muy finas en determinados puntos, se caracteriza por la presentación baja resistencia eléctrica y alta conductividad, con el objetivo de regularizar la energía que fluye por los meridianos de acupuntura (canales bioeléctricos), para el alcance de resultados de prevención o tratamiento además como una acción analgésica y reguladora de las funciones fisiológicas; la acupuntura y la digitopuntura son variantes de la medicina natural China, integrada en un complejo sistemas de conocimiento soportados por patrones etiológicos de línea materialista; un materialismo primitivo por sus orígenes, pero materialismo en su esencia, esto es referido al caso de la teoría de interrelación entre el Ying y el Yang; los cinco elementos naturales, la energía y los líquidos corporales. Para llegar al diagnóstico; al igual que la medicina de origen occidental; el facultativo tradicionalista efectúa una serie de pasos para encontrar y relacionar todo un conjunto de síntomas y signos , que luego de un análisis llegar a la conclusión de un diagnostico etiológico ; debiendo para realizar un adecuado tratamiento en acupuntura y ditopuntura es especifico el diagnostico tradicional que permite seleccionar de manera correcta los puntos que requieran ser estimulados; con la salvedad de que los giros en el sentido de las manecillas del reloj tonifican y en contra 


\section{Aplicación de la medicina natural y tradicional en odontología}

Vol. 3, núm. 2., (2019)

Héctor Gonzalo Macías Lozano; Rosendo Eduardo Loza Menendez; Davina Guerrero Vardelly

relajan (Pascual Casamayor, Pérez Campos, Morales Guerrero, Castellanos Coloma, \& Gónzalez

Heredia , 2014), (Bellon Leyva, Echarry Cano, \& Aldana Bello, 2013)

Terapia floral:

En este tipo de terapia las llamadas esencias florales tienen la capacidad de curar ya que son de la infinita energía universal, energía positiva extraída de los capullos de flores silvestres que ayudan a retornar $\mathrm{r}$ un camino equivocado, fortaleciendo $\mathrm{y}$ estimulando las cualidades positivas que tiene el ser humano dentro de sí. Como una información de alto precio es que, en el curso del año 1930, el médico galés Edward Bach, dedicó sus estudios a las propiedades medicinales de una enorme variedad de flores y con ellas organizó su propuesta terapéutica.

\section{Fototerapia:}

Como su etimología lo enmarca es la utilización de plantas, o partes de ellas, con finalidades terapéuticas, siendo utilizada por los animales y el propio hombre desde tiempo prehistórico. La mayor parte de los fármacos en la actualidad están basados en los principios activos de las plantas. (presencias de los plastidios, especialmente la clorofila); es la ciencia que estudia de una manera científica la utilización de las plantas que tradicionalmente se han usado para tratamiento. Esta ciencia exhibida como medicina herbaria, es la forma más antigua de atención médica conocida por la humanidad. Las plantas que emplea la población en la actualidad como medicamento vegetal no han sido estudiadas, sistemática y rigurosamente; por lo que debe haber continuación en el desarrollo de programas y proyecto de trabajo que encaminen el estudio, desde bases científica referentes a las propiedades curativas de estas plantas para el enriqueciendo 


\section{Aplicación de la medicina natural y tradicional en odontología}

Vol. 3, núm. 2., (2019)

Héctor Gonzalo Macías Lozano; Rosendo Eduardo Loza Menendez; Davina Guerrero Vardelly

el arsenal terapéutico. (Pascual Casamayor, Pérez Campos, Morales Guerrero, Castellanos Coloma, \& Gónzalez Heredia, 2014)

Este espacio hacemos proposiciones de algunas preparaciones de fitofarmarmacos que pueden ser utilizados por la población, esto pueden prepararse de diferentes formas.

Formas de preparación

Los fitofármacos pueden preparase de diferentes formas: una de ellas es la tintura o el extracto fluido dependiendo de la concentración de esta preparación:

1. Tintura: preparación hidroalcóholica hasta tres diluciones.

2. Extracto fluido: a partir de la cuarta dilución. Es más concentrado, por lo que se receta en gotas.

También pueden ser preparados en las casas, para un uso no mayor de 24 h, en diferentes formas:

1. Cocimientos: planta completa parte de ella hervida.

2. Infusión: agua recién hervida y agregar planta.

3. Macerado: machacar y echar agua hervida u otro líquido.

En caso de preparación casera, se deben tener en cuenta ciertas indicaciones como:

- No almacenar en vasijas metálicas.

- No usar por tiempo prolongado.

- No mezclar las plantas (Bellon Leyva, Echarry Cano, \& Aldana Bello, 2013) 


\section{Aplicación de la medicina natural y tradicional en odontología}

Vol. 3, núm. 2., (2019)

Héctor Gonzalo Macías Lozano; Rosendo Eduardo Loza Menendez; Davina Guerrero Vardelly

\section{Ozonoterapia:}

El ozono fue descubierto por el químico alemán Cristian Frederick, en la Universidad de Basilea, Suiza; el ozono (O3), está en la atmósfera a manera natural en forma de oxígeno alotrópico (propio relacionado con la propiedad de algunos elementos como el carbono, azufre o el fosforo). Referencias bibliográficas testifican que las primeras experiencias del uso del uso del ozono en medicina, data de 1915 a 1918, ocurrido en uno de los periodos de las primeras guerras mundiales, informando que cuando el doctor R. Wolff comenzó en Alemania a realizar las curas de ozonoterapia para la limpieza y desinfectar las llagas supurantes observo un efecto bactericida "sobre las infecciones polimicrobianas", así como una rápida cicatrización de heridas sépticas.

La molécula de ozono al estar dispersa en la atmósfera es tocada por los rayos ultravioleta; cayendo a la tierra repartiéndose por todos los contornos y purificando el agua y aire; así como también descomponiendo las bacterias y los hongos. Tiene un color azul tenue, lo cual es causa del color de los mares y cielo El ozono es reconocido internacionalmente como un poderoso oxidante de la naturaleza, tiene poder para destruir bacterias, tal es el caso que unos pocos microorganismos por litro son suficientes para destruir cepas o colonias bacterianas.

Se ha demostrado en estudios que la ozonolosis promueve la detoxificacion orgánica de una gran cantidad de toxinas, que muchas de ellas carcinogénicas.

Aunque tiene muchas aplicaciones, entre los que se encuentra las industriales solo se tratan al uso odontológico. (Bellon Leyva, Echarry Cano, \& Aldana Bello, 2013) 


\section{Aplicación de la medicina natural y tradicional en odontología}

Vol. 3, núm. 2., (2019)

Héctor Gonzalo Macías Lozano; Rosendo Eduardo Loza Menendez; Davina Guerrero Vardelly

\section{Medicina natural y tradicional en la odontología.}

Asumiremos en este gran espectro de la MNT la aplicación mantenida de esta en el ángulo de la Odontología. Con la entrada de la MNT en la Odontología se produce un vertiginoso cambio en el enfoque terapéutico de las afecciones del complejo bucomaxilofacial. En estos actuales tiempo la MNT es aplicada de forma generalizada en los servicios odontología, integrándose progresiva y favorablemente a las posibilidades terapéuticas para la solución de disimiles problemas de salud bucal, así como a la realización de procederes formales de los tratamientos odontológicos; detallando que en ocasiones se tienen dificultades contributivas a que no pueda ser sea aplicada en cada ocasión en que pudiera ser indicada. (Guillaume Ramírez, Ortiz Gómez, Álvarez Artímez, \& Marín Quintero, 2017)

La expuesta y probada efectividad de la MNT en pacientes que acuden a los servicios de salud odontológicos, ha posesionado y extendido su uso durante estas últimas décadas sostenida de manera concurrente en todos los países de América Latina, observándose asi su exitoso desarrollo. (Cardentey García, 2015)

La Medicina Natural y Tradicional (MNT) tiene entre sus propósito prevenir y tratar las enfermedades mediante la activación de las propias capacidades o de los recursos biológicos naturales con que cuenta el organismo humano; armonizando a este con la naturaleza; de ahí esmerada utilización de ejercicios, dietas y plantas. Es de amplitud referida el número de métodos y procedimientos que abarcan su empleo y su efecto sobre el hombre sano y el enfermo, permitiendo el alcance de un lugar cimero en el amplio depósito terapéutico del paciente en odontología. (Cardentey García, 2015) 


\section{Aplicación de la medicina natural y tradicional en odontología}

Vol. 3, núm. 2., (2019)

Héctor Gonzalo Macías Lozano; Rosendo Eduardo Loza Menendez; Davina Guerrero Vardelly

Siguiendo la marcha de este tema, hacemos referencias obligadas al empleo de la Medicina Natural y Tradicional en el tratamiento Odontológico.

Plantas más utilizadas en las urgencias odontológicas :(lo registrado en los paréntesis es el nombre científico de las plantas):

- Romero: (Rosmarines officinalles L)

a. Propiedades: antiinflamatorio y cicatrizante.

b. Indicaciones: aftas bucales.

c. Formas: cocimiento, infusión y extracto fluido.

d. Uso: 10 gotas en medio vaso de agua, colutorios 2 o 3 veces al día.

- Caléndula. (Caléndula officinalles L).

a) Propiedades: antiinflamatorio, antibacteriano, cicatrizante y repitelizante.

b) Indicaciones: aftas bucales, heridas de la mucosa bucal, quemaduras y colutorios.

c) Forma: tintura.

d) Uso: 10 gotas en medio vaso de agua, colutorio 3 veces al día.

- Sábila. (Aloe vera).

a) Propiedades: cicatrizante, antiinflamatorio, regenerativo y bio estimulante.

b) Indicaciones: aftas, GEHA y gingivitis decamativa.

c) Forma: crema y tintura. Puede durar en frío 7 días.

d) Uso: aplicación tópica. 


\section{Aplicación de la medicina natural y tradicional en odontología}

Vol. 3, núm. 2., (2019)

Héctor Gonzalo Macías Lozano; Rosendo Eduardo Loza Menendez; Davina Guerrero Vardelly

La aloína está en lo verde de la planta. Al congelarse pasa al cristal, este se pica y se aplica.

- Romerillo. (Bidens pilosa L).

a. Propiedades: cicatrizante, antiinflamatorio, antifúngico y antibacteriano.

b. Indicaciones: estomatitis subprótesis, odontalgia, aftas, GEHA y GUNA.

c. Forma: tintura o extracto fluido, colutorios 3 veces al día, zumo 3 veces al día más efectivo en estomatitis subprótesis. Crema, efectiva en aftas.

d. Uso: se utiliza toda la planta. Se debe filtrar.

- Ajo. (Allium sativumL). (bulbos).

a. Propiedades: analgésico, desinfectante, antiviral y antifúngico.

b. Indicaciones: odontalgias.

c. Forma: tintura.

d. Uso: una bolilla en la cavidad.

- Manzanilla. (Matricaria chamonilla L). (flores y hojas secas).

a. Propiedades: antiinflamatorio, antibacteriana, antifúngica, antiviral, antiulcerosos, antialérgico y analgésico.

b. Indicaciones: irritaciones de cualquier tipo.

c. Forma: colutorios y crema 2 veces al día. Tintura hasta el $20 \%, 20$ gotas en $200 \mathrm{~mL}$ de agua hervida. Extracto fluido, 10 gotas en $200 \mathrm{~mL}$ de agua. 


\section{Aplicación de la medicina natural y tradicional en odontología}

Vol. 3, núm. 2., (2019)

Héctor Gonzalo Macías Lozano; Rosendo Eduardo Loza Menendez; Davina Guerrero Vardelly

- Llantén mayor. (Ç Plantago mayor L.)

a. Propiedades: antiinflamatoria, astringente, antihemorrágico, antialérgico y bacteriostático.

b. Indicaciones: gingivitis crónica, aftas bucales,GEHA, otras ulceraciones de la mucosa bucal. Odontalgia, alveolitis, y colutorio antiséptico.

c. Forma: colutorios y crema 2 veces al día. Tinturahasta el $20 \%, 20$ gotas en $200 \mathrm{~mL}$ de agua hervida. Extracto fluido, 10 gotas en $200 \mathrm{~mL}$ de agua. (Bellon Leyva, Echarry Cano, \& Aldana Bello, 2013)
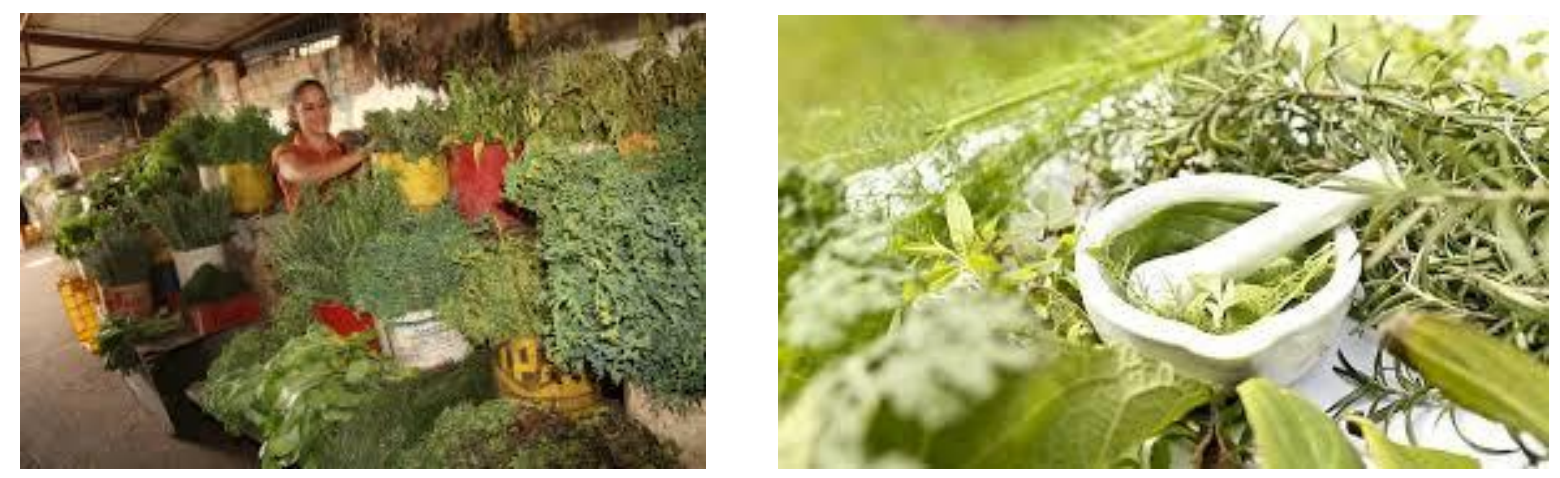

Apiterapia: Desde tiempos remotos la apiterapia ha sido utilizada. Altamente consumida en el campo de la medicina, principalmente en la Odontología; es la rama de la medicina que pone en uso la aplicación de los productos de las abejas en el tratamiento de las enfermedades; actualmente estos insectos brindan seis productos provenientes de la colmena: miel, jalea real, cera, polen, veneno de abeja (apitoxina) y propóleos. Cito (...) Según Moisés Asís "la apiterapia es la disciplina encargada del cuidado de la salud y el tratamiento y curación de las enfermedades mediante el consumo y aplicación de los productos apícolas. Ya que mayormente se habla del propóleos, por ser una de las variantes más aplicada en odontología, ya que cumple funciones 


\section{Aplicación de la medicina natural y tradicional en odontología}

Vol. 3, núm. 2., (2019)

Héctor Gonzalo Macías Lozano; Rosendo Eduardo Loza Menendez; Davina Guerrero Vardelly

mecánicas, de amortiguar vibraciones, aislamiento térmico, y de desinfección, tanto en las celdillas donde van a nacer las crías que son esterilizadas con propóleos como en todo el interior y entrada de la colmena. Posee propiedades antiinflamatoria, antitóxica, bacteriostática, bactericida, y cicatrizante, así como una más que probada acción anestésica. No debe ser de uso en pacientes alérgicos a las picadas de abejas. (Gutiérrez González \& Batista Herrera, 2013)

Tiene una composición química muy variada determinada por:

- Flora del área ecológica.

- Ciclos evolutivos de las plantas proveedoras de resinas, que ocasionan cambios en sus concentraciones.

- Microorganismos presentes en el entorno geográfico.

- Factores climatológicos.

Formas de presentación. del propóleos

Puede presentarse en varias formas como:

- Cremas.

- Talcos.

- Óvulos.

- Supositorios.

- Tintura.

- Extracto fluido. 


\section{Aplicación de la medicina natural y tradicional en odontología}

Vol. 3, núm. 2., (2019)

Héctor Gonzalo Macías Lozano; Rosendo Eduardo Loza Menendez; Davina Guerrero Vardelly

Indicaciones y uso en Odontología.

Entre sus indicaciones fundamentales tenemos:

- En operatoria:

a. Barniz para fondos.

b. Limpieza de campo operatorio.

- En exodoncia:

a. Después de exodoncias traumáticas.

b. Cura de alveolitis. Se puede utilizar en tintura o en extracto.

- En endodoncia:

a. Sedante previo a recubrimientos.

b. Irrigar conductos. Diluido en agua destilada.

c. Tratar fístulas. Extracto al $5 \%$

- En cirugía:

Preintervenciones y posintervenciones quirúrgicas.

Asepsia del campo.

- Después de destartraje, en forma de tintura.

- Lavado de fosas. 


\section{Aplicación de la medicina natural y tradicional en odontología}

Vol. 3, núm. 2., (2019)

Héctor Gonzalo Macías Lozano; Rosendo Eduardo Loza Menendez; Davina Guerrero Vardelly

- Control de placa. Como colorante.

- Hiperestesia dentinal. Tintura a más de $10 \%$.

En prótesis

- Indicada en el tratamiento de estomatitis subprotésica.

\section{Ozonoterapia.}

Efectos del ozono:

Antinflamatorio.

- Analgésico.

- Inmunosupresor.

- Cicatrizante.

- Bactericida.

- Virucida.

- Fungicida.

Indicaciones:

- Gingivitis ulceronecrotizante aguda.

- Gingivoestomatitis herpética aguda.

- Estomatitis aftosa recurrente.

- Úlceras traumáticas. 


\section{Aplicación de la medicina natural y tradicional en odontología}

Vol. 3, núm. 2., (2019)

Héctor Gonzalo Macías Lozano; Rosendo Eduardo Loza Menendez; Davina Guerrero Vardelly

- Conductos radiculares infectados.

- Cura de alveolitis.

- Barniz para cavidades.

- Cura en extracciones traumáticas.

- Estomatitis subprótesis.

\section{Contraindicaciones}

- Pacientes con tratamientos prolongados grandes dosis de vitamina A E.

- Pacientes con tratamiento de alopurinol. (Bellon Leyva, Echarry Cano, \& Aldana Bello, 2013)

\section{Acupuntura y digitopuntura.}

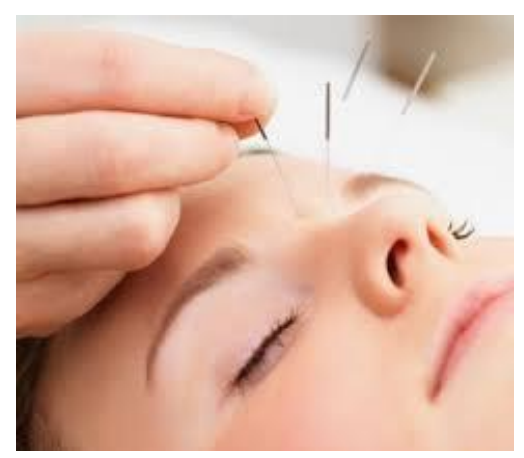

Son conocidos diferentes métodos terapéuticos aplicables como son; por presión digital, termopuntura, masajes y ventosas. En la actualidad son combinados con métodos eléctricos, láser, inyección de medicamentos, entre otros. Los puntos de acupuntura se encuentran en la trayectoria de los meridianos principales, recibiendo el nombre de dicho meridiano, agregándose el número de orden, según circule en ellos la energía. (Acosta Navarro, Trujillo Alayón, Travisas Herrera, \& Delgado Fernández, 2012)

Muchas son las patologías en odontología que son ser tratadas de manera urgente dentro de todas ellas generalmente el síntoma que predomina es el dolor; realizado por el médico el diagnóstico en el paciente, sigue una serie de normas para realizar el esquema de tratamiento; 


\section{Aplicación de la medicina natural y tradicional en odontología}

Vol. 3, núm. 2., (2019)

Héctor Gonzalo Macías Lozano; Rosendo Eduardo Loza Menendez; Davina Guerrero Vardelly

haciendo la selección los puntos de acupuntura para proceder a presionar o pinchar la que se encuentran en el área afectada (puntos locales), que se correspondan con los meridianos; seleccionar los puntos que se encuentren situados distalmente (puntos dístales) a la patología a tratar y se pueden encontrar áreas reducidas de dolor que no correspondan con puntos de meridianos o fuera de ellos ( y que según los asiáticos son zonas que deben ser puncionadas, "tomar el lugar doloroso por un punto a tratar", a estos puntos se les llama Ah-Shi ). De estos meridianos a seleccionar para el tratamiento se encuentran los ubicados en el área de la cara como son: estómago, intestino delgado, intestino grueso, vesícula biliar, triple función, vaso concepción y vaso gobernador. (Bellon Leyva, Echarry Cano, \& Aldana Bello, 2013)

Puntos de acupuntura más usados en Odontología:

$\checkmark$ IG4: mano, entre dedo pulgar e índice, es el punto más analgésico: cefalea, dolores oftálmicos, insomnio, dolores en la cara y los dientes.

$\checkmark$ E3: borde inferior del ala nasal, odontalgias, neuralgias y parálisis facial, glaucoma y miopía.

$\checkmark$ E7: debajo del arco zigomático, se aplica en odontalgias, artritis de la ATM, neuralgia del trigémino, parálisis facial y trastornos auditivos.

$\checkmark$ E44: entre el segundo y tercer dedo. Analgésico para miembro inferior, cefalea, epigastralgia y amigdalitis.

$\checkmark$ C7: extremo interno, de la muñeca, punto especial, modifica respuesta psíquica, es tranquilizante, tiene efectos en la ansiedad, en palpitaciones y estados de histeria. 


\section{Aplicación de la medicina natural y tradicional en odontología}

Vol. 3, núm. 2., (2019)

Héctor Gonzalo Macías Lozano; Rosendo Eduardo Loza Menendez; Davina Guerrero Vardelly

$\checkmark$ ID8: En la cara posterior de la articulación del codo con el codo flexinado a $90^{\circ}$. Se aplica en la gingivitis.

$\checkmark$ VG 26: ubicado debajo del tabique nasal. Especial en emergencias, como shock, desmayos, lipotimia, histeria, epilepsia, palpitaciones, puede aplicarse dígito presión. (Acosta Navarro, Trujillo Alayón, Travisas Herrera, \& Delgado Fernández, 2012)

Estudios investigativos realizados por Guillaume Ramírez (2017), agendo; que casi la totalidad de los odontólogos encuestados expresan haber aplicado la Medicina Natural y Tradicional en el tratamiento odontológico; adema s que las principales dificultades para su aplicación fueron el poco conocimiento sobre estas terapias y no disponer regularmente de los recursos necesarios en la consulta. En revisiones efectuadas al respecto se contactó lo siguiente (...) Según Cardentey García (2015), la Medicina Natural y Tradicional más utilizada en odontología fue la fitoterapia; la manzanilla y la caléndula, acotando que fueron las plantas medicinales más representativas en su estudio.

La periodontitis crónica es una enfermedad infecciosa de alta prevalencia que afecta los tejidos periodontales, causando inflamación, pérdida de inserción clínica y pérdida ósea es de progresión lenta. Posteriormente los investigadores Arteaga, Dávila, Gutiérrez, Sosa, Albarrán, Isla, Díaz N .( 2017) dieron muestra de que el gel de manzanilla y llantén junto con la terapia convencional proporciona beneficios en la recuperación de la salud del periodonto; permitiendo que los tejidos periodontales cicatricen en un periodo corto de tiempo. (Artega S, Gutiérrez R, Albarrán G, \& Díaz, 2017) 


\section{Aplicación de la medicina natural y tradicional en odontología}

Vol. 3, núm. 2., (2019)

Héctor Gonzalo Macías Lozano; Rosendo Eduardo Loza Menendez; Davina Guerrero Vardelly

Resumiendo, la Medicina Natural y Tradicional (MNT) ayudará a las autoridades sanitarias a encontrar soluciones que propicien una visión más amplia respecto al mejoramiento de la salud y la autonomía de los pacientes.

\section{Bibliografía.}

Acosta Navarro, M., Trujillo Alayón, A., Travisas Herrera, E. M., \& Delgado Fernández, R. (2012). La acupuntura y su aplicación en estomatología .Revista Cubana de Estomatología, 49(2),158-166.

Artega S, D. L., Gutiérrez R, S. L., Albarrán G, I. M., \& Díaz, N. (2017). Efectividad del Gel de Manzanilla y LLanten como terapia coadyuvante en el tratamiento de la periodontitis crónica.Actaa Bioclinica 7(13).

Bellon Leyva, A., Echarry Cano, O., \& Aldana Bello, Y. (2013). Aplicación de la Medicina Natural y Tradicional en Estomatología.Capitulo 30. En G. Gónzalez Anaya, \& M. Montero del Castillo, Estomatología General Integral. La Habana.Cuba: Editorial Ciencias Médicas. ECIMED.

Cardentey García, J. (2015). Empleo de la medicina natural y tradicional en el tratamiento estomatológico.Revista Archivo Médico de Camaguey,19(3),316-321.

Guillaume Ramírez, V., Ortiz Gómez, M., Álvarez Artímez, I., \& Marín Quintero, M. (2017). Aplicación de la Medicina Natural y Tradicional y dificultades para su uso en Estomatología .Revista Cubana de Estomatología ,54(2),1-12.

Gutiérrez González, A. M., \& Batista Herrera, M. d. (2013). Usos de la apiterapia en Estomatología .Correo Cientifico Médico,17(1).

Nicot Cos, R. F., Nicot Mesa, D., Masó Baro, M., \& Balbuena Daudinot, Y. (2014). Guía actualizada sobre la aplicación de la Medicina Natural y Tradicional en Estomatología. Revista Portales Médicos.

OMS. (2013). Estrategia de la OMS sobre medicina tradicional 2014-2023. Recuperado el 9 de octubre de 2018, de http://apps.who.int/medicinedocs/documents/s21201es/s21201es.pdf.

Pargas Torres, F. (2005). Enfermería .La Medicina Tradicional y Natural. La Habana Cuba: Editorial Ciencias Médicas. ECIMED. 


\section{Aplicación de la medicina natural y tradicional en odontología}

Vol. 3, núm. 2., (2019)

Héctor Gonzalo Macías Lozano; Rosendo Eduardo Loza Menendez; Davina Guerrero Vardelly

Pascual Casamayor, D., Pérez Campos, Y. E., Morales Guerrero, I., Castellanos Coloma, I., \& Gónzalez Heredia, E. (2014). Algunas consideraciones sobre el surgimiento y la evolucion de la medicina natural y tradicional .MEDISAN,18(10),147-1474.

$$
\text { (c) (1) (9)( }
$$

RECONOCIMIENTO-NOCOMERCIAL-COMPARTIRIGUAL

CC BY-NC-SA

ESTA LICENCIA PERMITE A OTROS ENTREMEZCLAR, AJUSTAR Y CONSTRUIR A PARTIR DE SU OBRA CON FINES NO COMERCIALES, SIEMPRE Y CUANDO LE RECONOZCAN LA AUTORÍA Y SUS NUEVAS CREACIONES ESTÉN BAJO UNA LICENCIA CON LOS MISMOS TÉRMINOS. 